\title{
SOCIEDADE DE RISCO, BIOÉTICA E PRINCÍPIO DA PRECAUÇÃO
}

\author{
RISK SOCIETY, BIOETHICS AND THE PRECAUTIONARY PRINCIPLE
}

\author{
${ }^{1}$ Marcelo Pereira Dos Santos
}

\section{RESUMO}

A dinâmica da medicina tem provocando grande arrepio na sociedade, em virtude dos avanços alcançados no âmbito da biomedicina e da genética que proporcionaram eventos dantes impensados como as técnicas de reprodução assistida, clonagem terapêutica, cirurgias para transmutação de sexo, bem como dos procedimentos clínicos voltados ao prolongamento da vida. Esses eventos não se dão sem provocar dilemas éticos que impõem uma reflexão em torno dos limites e graus de aceitabilidade quanto aos métodos e práticas utilizados por profissionais da saúde, biólogos, cientistas, farmacêuticos dentre outros envolvidos na manipulação de material genético e experimentações com seres humanos. Nessa perspectiva, o presente ensaio, a partir da apreciação analítica dos paradigmas da Bioética, promove a correlação entre dignidade humana, progresso científico e direitos fundamentais das futuras gerações sob os influxos decorrentes dos avanços da ciência e da tecnologia numa sociedade caracterizada pelo risco e a ambivalência. A análise das questões suscitadas é promovida com a utilização da metodologia dialético-descritiva, consubstanciada na pesquisa bibliográfica em torno das questões supramencionadas, envolvendo livros, artigos, dissertações e teses publicadas nos dez últimos anos. O referencial teórico tem assento na concepção de riscos e ambivalências, delineados por Ulrich Beck, Franz Josef Brüseke, Anthony Giddens, Zygmunt Bauman. O estudo aponta a compreensão da necessária incidência bioética do princípio da precaução como farol ético norteador do progresso técnico-científico e a necessária conciliação entre experimentações e legitimidade das escolhas para a manutenção e evolução da espécie humana.

Palavras-chave: Riscos, Ciência, Bioética, Dignidade, Precaução

\footnotetext{
${ }^{1}$ Graduado em Direito pela União Educacional do Planalto Central, Brasília - DF (Brasil). Soldado da Polícia Militar de Brasília - DF (Brasil). E-mail: marcelo.pereira.adm.ufrrj@gmail.com
} 


\begin{abstract}
The dynamics of medicine has causing great shiver in society, given the progress made in the context of biomedicine and genetic events that provided before thoughtless as the assisted reproduction techniques, therapeutic cloning, surgery for transmutation of sex, as well as focused clinical procedures prolonging life. These events do not occur without causing ethical dilemmas that require a reflection on the limits and degrees of acceptability in the methods and practices used by health professionals, biologists, scientists, pharmacists and others involved in the manipulation of genetic material and trials with humans. From this perspective, this paper, from the analytical assessment of the Bioethics paradigms, promotes the correlation between human dignity, scientific progress and rights of future generations under inflows arising from advances in science and technology in a society of risk and the ambivalence. The analysis of the issues is promoted with the use of dialectical-descriptive methodology, based on the literature about the above issues, involving books, articles, dissertations and theses published in the last ten years. The theoretical framework sits in the design of risks and ambivalences, outlined by Ulrich Beck, Franz Josef Brüseke, Anthony Giddens, Zygmunt Bauman. The study aims to understand the necessary effect bioethics of the precautionary principle as a guiding ethical beacon of scientific and technical progress and the necessary reconciliation between trials and legitimacy of choices for the maintenance and evolution of the human species.
\end{abstract}

Keywords: Risk, Science, Bioethics, Dignity, Caution 


\section{INTRODUÇÃO}

A racionalidade aguça a curiosidade humana e fez do ser humano um investigador da sua própria natureza. Ao longo da sua existência utilizou de vários métodos e técnicas para descobrir a face oculta do universo habitado e inóspito. Essa tendência por querer ir sempre mais além, com o auxílio dos instrumentos que a ciência e a técnica possibilitaram, fez com que o ser humano superasse as barreiras do conhecimento para atingir resultados nunca antes alcançados.

O encantamento pela ciência o tornou incansável observador das mutações ocorridas na vida dos seres e no ambiente ao seu redor. Contudo, e em paralelo, acabou seduzido pelo mercado de bens e serviços que passam a dar a tônica de uma sociedade reificada e fundada no lucro. Esta combinação entre os avanços no campo da ciência e da técnica, mormente no que diz respeito à biotecnologia e as demandas de uma sociedade de mercado leva a que filósofos, juristas, religiosos e integrantes da comunidade científica passem a refletir sobre as questões éticas em torno das experimentações envolvendo o ser humano, uma vez que o panorama das pesquisas representa ameaça para a sociedade contemporânea e prospectiva.

Nessa ótica, o estudo aqui proposto recai sobre exame da Bioética na perspectiva da sociedade de risco, com o objetivo da definição de novos paradigmas que ao mesmo tempo que não impeçam, o progresso científico, tendo como eixo basilar a dignidade humana salvaguardem os direitos fundamentais das atuais e futuras gerações. Para tal, os autores privilegiaram a metodologia dialético-descritiva, consubstanciada na pesquisa bibliográfica de obras doutrinárias, legislação pertinente, teses, dissertações e artigos extraídos de periódicos, publicados nos dez últimos anos.

O eixo temático foi delineado com apoio no referencial teórico assentado sobre o pensamento de Ulrich Beck, Franz Josef Brüseke, Anthony Giddens, Zygmunt Bauman, devido à aproximação da abordagem sistemática voltada aos desafios de uma sociedade marcada por ambivalências, contingências e incertezas.

Frente às perplexidades provocadas pelas experimentações com seres humanos e das questões bioéticas suscitadas, o trabalho é fixando no seguinte problema: em que medida é possível conciliar o progresso científico e tecnológico com o resguardo da dignidade humana?

Inicialmente, é explorada a trajetória baumaniana da transição da modernidade sólida para a pós-modernidade fluida, traçando algumas características presentes em cada momento, a fim de compreender a atmosfera das incertezas e da aleatoriedade. 
Em seguida, o foco se volta para concepção de "sociedade de risco e do conhecimento", tomando por base os ensinamentos dos autores mencionados. Nesse ponto, visa-se demonstrar os efeitos da onda biotecnológica que atravessa o século XX e alcança o século XXI.

O próximo item é reservado à investigação da bioética como referencial para a discricionariedade técnica e fundamento para os métodos e práticas utilizados por profissionais da saúde, biólogos, cientistas, farmacêuticos dentre outros envolvidos na manipulação de material genético e experimentações com seres humanos. Busca-se aqui desvendar a dupla dimensão dos limites da vida.

$\mathrm{Na}$ última parte do ensaio, verifica-se os princípios fundamentais da Bioética e a relevante intervenção da AMM (Associação Médica Mundial) sobre os métodos e práticas utilizados na experimentação com seres humanos. Ademais, é dado destaque ao princípio da precaução em razão da sua relevância para o avanço da ciência em benefício da vida humana, animal e ambiental.

\section{TRANSITANDO PELA MODERNIDADE E PÓS-MODERNIDADE}

As descobertas alcançadas pelos seres humanos, fruto do avanço da ciência combinada com a técnica, trouxeram a reboque a necessidade do estabelecimento de limites e controle sobre o desconhecido, causando a sensação de medo naqueles que enxergavam riscos potenciais em torno das novas experiências. Portanto, diante dos perigos abstratos e concretos, a mensuração das contingências ganhou destaque na órbita social, conduzida pelo desejo de ampliar os ganhos e minimizar as perdas.

Enfrentar as incertezas e a atmosfera aleatória era algo inevitável para atingir a evolução e o progresso da pessoa enquanto ser gregário. O mundo já não era mais estático, como se pensava, mas sim uma esfera dinâmica, girando em torno do próprio eixo (SILVEIRA, 2002, p. 408-409). Ainda que consciente das consequências indesejadas e/ou não conhecidas, a insatisfação do homem sobre o universo concreto estimulou a corrida por um plano ideal.

Era preciso superar a si mesmo, descobrindo técnicas e ferramentas que lhe permitisse fazer mais do que a sua capacidade. A infindável busca pela superação da realidade tangível deu causa a inúmeras mudanças no âmbito da cultura ocidental, sobretudo em decorrência da Revolução Industrial, frente ao estímulo da produção e comercialização de bens e serviços, circunstâncias que representaram a transição da sociedade tradicional para a fase da 
modernidade - que irão redundar, pós-Segunda Guerra, no advento de uma sociedade de massas e de consumo cada vez mais exagerado e a ampliação das exigências do mercado. (RANDALL JR., 1976).

A luta pelo poder econômico e territorial deu origem a duas grandes guerras e, paralelamente, conduziu à ascensão tecnológica que repercutiu sobre todas as nações. Consequentemente, as fronteiras foram rompidas e o fenômeno da globalização superou as distâncias entre o ocidente e o oriente, o norte e o sul, o leste e o oeste, o sudeste e o noroeste. As técnicas foram sendo aperfeiçoadas para melhor atender às demandas de um mundo novo, marcado por ambivalências, assim como impregnado por valores distintos, desapegado aos mitos e envolvido pelo ceticismo.

Essa sucessão de eventos acabou por desaguar numa dimensão largamente evoluída da sociedade, denominada pós-modernidade , cujas bases se assentaram sobre a desconfiança, imprecisão, insegurança, ambiguidade, obscuridade, inconsistência, vulnerabilidade, precariedade e instabilidade em todos os campos da ciência. Partindo dessa premissa, Ulrich Beck (1986) concebeu o termo "sociedade de risco" para alertar à comunidade quando ao malestar causado pelo apego à superação dos limites da vida e retratar o acidente nuclear ocorrido na cidade de Chernobyl (Ucrânia), acompanhado por Patrick Lagadec (1981) que cunhou a expressão "civilização de risco", seguido também por Patrick Peretti-Watel (2000), o qual deu destaque à "sociologia do risco" e Robert Castel (2003), sociólogo francês que descreveu a “insegurança social” (MOREIRA NETO, 2008, p.140).

Se por um lado os avanços científicos e tecnológicos superaram expectativas, tornando a vivência comunitária mais ágil e cômoda, por outro, provocaram perdas incomensuráveis à família, ao ecossistema, aos direitos individuais e coletivos, à paz entre os povos, aos valores religiosos, à memória cultural e à privacidade. Estes são apenas alguns dos reflexos da sociedade pós-industrial que irão se propagar por gerações até que os seres humanos sucumbam diante do esforço contínuo para conquista da perfeição (BECK, 2010, p. 44).

\section{SOCIEDADE DE RISCO E DO CONHECIMENTO}

Enquanto na sociedade industrial a lógica da produção de riqueza dominava a geração das contingências, na fase da corporificação social do risco essa relação se inverteu, ou seja, na modernidade tardia ou pós-modernidade o acúmulo de fortunas passou a ser acompanhado, sistematicamente, pela eclosão das probabilidades trágicas. O agravamento do cenário de 
incertezas se deu também em decorrência dos conflitos relacionados à indefinição e à distribuição dos perigos cientificamente criados (BECK, 2010, p.23).

Na modernidade desenvolvida, o signo do medo apresentou-se como produto das descobertas, experimentações e invenções, caminhando lado a lado com o avanço tecnológico, conforme as escolhas feitas pelo homem. Não se tratou de mera consequência ou resíduo de uma sociedade tradicional, a qual se concentrava nas necessidades imediatas para subsistência e bem estar, mas sim da busca do aperfeiçoamento das máquinas, dos seres, dos processos, das ferramentas, da vida em geral.

A dimensão social adquirida com o progresso da ciência promoveu um choque antropológico, suspendendo os conceitos de emancipação, nacionalidade, espaço e tempo. As conversões operadas entre os séculos XVIII e XXI demonstraram que as catástrofes não foram resultado das falhas, mas sim das forças destrutivas extraídas dos sistemas transformadores. As mortes e destruições ocorridas no mundo não se deram por conta da mera falta de cuidado, mas sim pela busca ao desconhecido e a corrida pelo desenvolvimento a qualquer preço. Os cientistas não poderiam ser equiparados a pessoas inocentes ou ignorantes e, além disso, as ações perigosas eram submetidas à medição, à análise teórica, à opinião de outros especialistas, bem como, contavam com estudos de impactos relacionados ao ambiente e ao indivíduo.

Os recursos do planeta foram subjugados e super explorados ao longo do século XX e, assim, transformados de fenômeno externo em interno, de manifestação predeterminada em fabricada. Ao longo de sua metamorfose tecnológico-industrial e de sua comercialização global, a natureza foi absorvida pelo sistema industrial. A dependência do consumo e do mercado caracterizou um novo tipo de sujeição universal. Essa diretriz se converteu em lei do modo de vida na civilização moderna.

A passagem do modelo de distribuição de riqueza na sociedade da escassez para a lógica da distribuição de riscos na modernidade tardia ou pós-modernidade ecoou historicamente sob os seguintes aspectos: a) se por um lado a tecnologia evoluiu para fabricação de novos produtos e serviços, por outro, foram produzidos, em paralelo, malefícios que atingiram a comunidade humana; b) a carência material dos indivíduos exigiu máximo esforço do Estado para garantia dos direitos, que não necessariamente ocorreu, na maioria das vezes; c) cada vez mais os órgãos estatais se viam incapazes de suplantar ou politicamente não comprometidos em prover, exclusivamente, todos os encargos impostos pelo período pósindustrial; e d) se tornara indispensável o apoio e a cooperação, consubstanciada na 
solidariedade social, por parte dos envolvidos nesse processo evolutivo, a fim de moderar as perdas e melhor gerir a máquina pública.

Outro aspecto relevante estaria ligado à percepção do sofrimento e opressão, decorrentes dos efeitos nocivos, provocados pelos produtos sistematicamente produzidos, por aqueles que os negavam tais desgraças. Novas fontes de riqueza (energia atômica, indústria química, tecnologia genética etc.) transformaram-se em (im)previsíveis nascentes de ameaças. A evidência dos vilipêndios à vida, oferecidos pelo mercado modernizante e pelas mercadorias evoluídas, proporcionou sentido anacrônico aos discursos encobridores das suas consequências degenerativas e perniciosas (BECK, 2010, p.62).

$\mathrm{O}$ homem passou a temer a si próprio. $\mathrm{O}$ crescente consumismo extravagante cegou a sociedade, que, ao tentar olhar para o horizonte, se viu impotente e submissa aos riscos gerados pelo seu comportamento. Graus de aceitabilidade foram concebidos para confortar os temores da onda tecnológica e progressista. Assim, por mais bem formadas e informadas, as pessoas aceitaram a circunstância do irreversível aniquilamento da espécie humana, transformando a ameaça projetada em perigo real. Nesse sentido, tornava-se nítido que a luta milenar por direitos fundamentais corresponderia a uma fatigante batalha do ser humano contra si mesmo.

A globalização tornou as fronteiras vulneráveis em meio ao silencioso e sorrateiro influxo repugnante da ação leviana. As decisões de cunho coletivo, e até individual, passíveis de potenciais danos ao interesse público, não mais se restringiriam as perspectivas internas ou endógenas, contextualizada perante determinada questão. A nova lógica exigira profunda sondagem quanto o alcance, o tipo e o teor das ameaças, círculos de pessoas atingidas, efeitos retardados, possíveis responsáveis, a repercussão nos casos de demandas por reparação entre outros ângulos.

Isso acabou demonstrando que o estudo do comportamento social e a teoria política da sociedade de risco seriam, em seu cerne, ciência do conhecimento e não sociologia da saber. Significa que estar-se-ia investigando nesse recente cenário de incompletudes, todos os amálgamas, incorporações e atores cognitivos, além das suas conflitivas absorções e enfrentamentos mútuos, seus fundamentos, suas pretensões, seus erros, suas irracionalidades, suas verdades e suas impossibilidades. Esse exercício, nem todos se esforçariam em fazer, pois, segundo os donos da sapiência, tais experiências já eram conhecidas dentro dos seus campos analíticos (BECK, 2011, p. 66).

A ocultação dos aspectos conflitivos, decorrentes das conquistas técnico-científicas, foi disseminada e se tornou patente. Os perigos invisíveis tornaram-se evidentes. Os danos 
decorrentes da manipulação química e biológica, antes imperceptíveis, converteram-se em um estado pungente aos olhos, o nariz e ouvido. O definhamento das florestas avançou em passos largos, as águas interiores foram contaminadas, os hidrocarbonetos foram despejados em quantidades incomensuráveis, carcaças de animais encharcadas de óleo ocuparam a paisagem das baías, a erosão desfigurou a natureza, a beleza arquitetônica dos edifícios foi desarranjada pela poluição. A mídia trouxe à tona uma sucessão de acidentes, escândalos e catástrofes causadas por materiais tóxicos. Os alimentos levados à mesa ganharam substâncias corrosivas à saúde e os bens de consumo multiplicaram em ordem numerosamente astronômica. Tudo isso ficou tão gritante que os responsáveis deixaram de apresentar argumentos convincentes às suas vítimas. "Hoje, sobram dúvidas se foram os riscos que se aguçaram ou se foi o olhar sobre eles" (BECK, 2010, p.66).

O berço dessa crise se deu em decorrência desse processo em que valores e tradições foram alterados. A junção da técnica com a ciência fez nascer um intenso ceticismo quanto aos pilares retilíneos da era industrial. Dessa forma, o fundamentalismo passou a ser visto como ameaça ao diálogo, bem como abrigo para potenciais violências (GIDDENS, 1994, p.12-13). O conteúdo fechado foi aberto e submetido à análise, surgindo daí respostas plurissignificativas que gerariam inumeráveis perguntas. Os especialistas buscaram extremar seus conhecimentos, mas as incertezas se tornavam ainda mais transbordantes.

A aceleração do crescimento veio nessa toada, acentuando a assimilação do risco ao lado da sua comercialização. O orçamento público sofrera frontais abalos devido às trincheiras construídas pelo Estado para combater o desequilíbrio ambiental, as epidemias, a desestabilização economia, a ineficiência das instituições etc. À medida que as contingências eram superadas se recriavam perigosas circunstâncias.

O progresso decorrente da industrialização - atingido no século XIX - fez a sociedade crer que ferramentas evoluídas conduziriam à segurança total, ocasionando o fim das incertezas. De modo reverso, o avanço tecnológico originara o "risco fabricado", conjuntura que merecera reflexão sobre as liberdades (GUERRA, 2009, p. 12).

Nesse contexto, Bauman (1999, p. 113) assevera que não se encontra, no que caracteriza como pós-modernidade, utilidade para os termos "certeza" e "segurança". Nada é conhecido com infalibilidade e qualquer coisa que seja sabida pode ser compreendida de modo diferente. Destarte, reverbera o autor que enquanto as convicções eram procuradas em outrora, nessa sociedade despida e penetrada pelos ciclos da ciência, o ato de "apostar se tornou uma regra" e o "arriscar" substituiu a "teimosa busca por objetivos" (BAUMAN, 1998, p. 36). 
Com amparo nesses dissabores e características dessa sociedade pós-moderna, o estudo é voltado para (re)configuração das pautas éticas, morais e jurídicas inerentes à manipulação da vida humana em prol da dignidade, do meio ambiente e do prudente progresso científico, o qual recomenda o diálogo, a participação, transparência e consensualidade.

\section{BIOÉTICA: DUPLA DIMENSÃO DOS LIMITES DA VIDA}

A Bioética é parte da Ética, ramo específico da filosofia, que se preocupa com as questões relativas à vida humana, disciplina própria do mundo moderno, no qual, com a mudança da perspectiva fundamentalmente religiosa do homem em perspectiva científica, operou-se uma transformação em sua visão: de uma visão mística do ser humano como o agente responsável no meio em que habita, para uma ótica biológica do ser como organismo que interage submetido a forças tanto biológicas quanto sociais.

A Bioética deita suas raízes etimológicas no grego, onde bios significa vida e o termo ethos quer dizer "modo de ser" ou "caráter", no sentido similar ao do "forma (s) de vida(s) adquirida(s) pelo homem".

Neologismo construído por V.R. Potter, biólogo e oncologista, em 1971, para descrever a ciência que tinha como objeto temas relacionados à ética ambiental e à medicina. A terminologia foi reproduzida por Hellegers, obstetra, fisiologista e demógrafo, na ocasião em que foi fundado o Joseph and Rose Kennedy Institute for the study of Human Reproduction and Bioethics (ROTANIA, 2001, p. 159).

A Ecoética e a Bioética revelam essas formas novas da ética aplicada que caracterizam a sociedade, a cultura e os valores morais da civilização contemporânea. A bioética tenta focalizar a reflexão ética no fenômeno vida. Configura-se como um saber interdisciplinar que reflete sobre os problemas relativos à vida humana em sua plenitude. Nela intervém a filosofia, a biologia, a medicina, o direito, a religião, a economia, a política e a sociologia.

Para Hans Jonas (1995, p. 125), a Bioética é uma nova ética, nascida a partir dos novos questionamentos e das necessidades levantados pelo biopoder humano. A ética tradicional estaria inserida num contexto universal limitado pela previsibilidade da vida humana, no qual o agir ético condicionava-se ao âmbito da proximidade e da urgência. No entanto, o desenvolvimento biotecnológico fez com que o alcance, os objetivos e as consequências da ação humana, determinados pela tecnologia, tomassem rumos tão inesperados e inimagináveis que a 
ética tradicional, segundo o autor, não se encontra em condições de abarcar. A fronteira até então identificável do limite entre o "natural" e o "artificial", entre "cidade" e "natureza", entre o que é para o "bem" e o que é para o "mal" diluiu-se. Nas palavras do autor:

\footnotetext{
"A cidade dos homens uma vez foi o ninho no mundo extra-humano, agora estende- se por toda natureza terrestre e lhe usurpa o lugar. Entre natural e artificial não existe mais diferença: o natural é absorvido pela esfera do artificial e ao mesmo tempo a totalidade dos artefatos, as obras do homem que influem sobre ele e por meio dele, gera uma "natureza" própria, quer dizer, uma necessidade com a qual a liberdade humana deve se confrontar em um sentido completamente novo. (...) Há uma outra lógica no agir ético: não aquela do ato em si mesmo, mas a dos seus efeitos últimos com a permanência do agir humano no futuro" (JONAS, 1995, p. 126)
}

Essa ideia permite uma interligação entre a bioética e sociedade de risco, havendo uma relação de causalidade, onde uma é consequência da outra. Dessa forma, a comunidade começou a se preocupar com os efeitos devastadores das ciências avançadas, composta por novos componentes, como: fórmulas recentemente criadas em laboratórios, instrumentos de alta tecnologia, ambientes sofisticados, mecanismo de última geração para coleta de amostras etc.

Tudo que é novo gera insegurança, e é esse o sentimento da sociedade pós-moderna quando se depara com fertilização in vitro, produção de seres híbridos, combinação de DNA, experiência científica em embriões, ameaça de holocausto nuclear, produção ou utilização de microorganismos geneticamente modificados, mudança de sexo, barriga solidária. Esses fenômenos geram questionamento quanto o limite da ciência. É bom lembrar que o artigo $5^{\circ}$, inciso IX, da Constituição Federal de 1988 traz como direito fundamental a liberdade científica.

A Bioética surgiu como uma nova disciplina, que a partir de um enfoque plural, coloca em consonância o conhecimento do denominado mundo biológico com a formação de atitudes e políticas comprometidas com o bem-estar da coletividade. Além das implicações decorrentes dos interesses econômicos e políticos que as matérias tratadas pela Bioética envolvem, as quais tem a ver com questionamentos que envolvem desde a chamada investigação "pura" até os problemas éticos de sua aplicação tecnológica.

Há um processo natural do se transformar da pessoa, composto por influências culturais, econômicas, políticas, valorativas e religiosas, mas que, com a chegada da revolução tecnológica (pós-industrial), passou a sofre influxos da biomedicina. Esse avanço deu ensejo a discussões sobre o princípio da vida dos indivíduos, a antecipação e distanciamento da morte, a engenharia genética, as terapias gênicas, os mecanismos de reprodução assistida, entre outros eventos que incrementam o risco. 
Juntamente com a pós-modernidade baumaniana, vieram doenças nunca antes conhecidas, intensa degradação ambiental, dúvidas quando à disponibilidade da vida, exposição da integridade física e fenômenos naturais de extrema proporção. Tais distúrbios ganharam amplitude em razão da busca por resultados imediatos e a tentativa de alcançar a inatingível perfeição.

As respostas para a solução dos males do Universo "evoluído" foram requisitadas às ciências médicas. Por conseguinte, "o uso generalizado de antibióticos e técnicas artificiais de respiração, popularizado nas décadas de cinquenta e sessenta do século passado", abriu um horizonte de possibilidades para prolongamento da vida humana (HECK, 2005, p. 125).

Segundo Martinez et al (2003, p. 662), foi atribuído a Carrel, em 1912, o prêmio Nobel de medicina para o desenvolvimento de diferentes técnicas em suturas vasculares. Medawar, no de 1940 sentou-se as leis básicas da imunologia o transplante. Voronoy teve lugar em 1933 o primeiro transplante de rim em seres humanos. O ano 1954 foi fundamental na história do transplante Rim a operação conduzida por Murray e Merrill ao obterem êxito com pacientes irmãos gêmeos monozigotos (univitelinos).

Não menos importante, Heck (2005, p. 125-126) aponta para a descoberta da técnica de depuração sanguínea, em 1961, pelo Dr. Belding Scribner, em Seattle, evento que gerou impasses entre médicos e demais operadores da saúde com a indução da morte de pacientes pela falta de acesso à máquina da hemodiálise. $\mathrm{O}$ autor também sinaliza a enorme transformação decorrente da introdução e popularização da pílula anticoncepcional no varejo, tal como a repercussão diante do possível planejamento familiar e profissional, circunstância esta, inimaginável até a década de 1960. Além disso, a afinação da técnica e a acessibilidade legal à interrupção da gravidez demandaram reformulações sobre a normatização das práticas de aborto.

No arvorar de uma nova Era, a comunidade científica foi compelida a refletir sobre os critérios, até então majoritariamente aceitos, acerca da morte cerebral, dentre outras agruras atinentes ao momento inicial e derradeiro da vida humana. Os desafios tomaram dimensões incontornáveis e, portanto, foram instituídos parâmetros mínimos para orientar a medicina, tais como primum non nocere (pelo menos não lesar) e salus aegroti suprema lex (o bem-estar do paciente em primeiro lugar).

Não bastava pensar os problemas sob os olhares das ciências médicas, pois inúmeros fatores determinavam uma investigação multifacetária, abrangendo diversos campos do 
conhecimento, a fim de alcançar a providências adequadas. Assim sendo, ficou evidenciada a crise da ética médica.

A Bioética partiu de um referencial para circunscrever os perigos e ameaças insuportáveis à sociedade, adotando a dignidade da pessoa humana como princípio fundamental, redimensionados nos ideais de não-maleficência, justiça, beneficência e autonomia, os quais foram registrados no Belmont Report, publicado, em 1978, pela National Commission for the Protection of Human Subjects of Biomedical and Behavioral Research (Comissão Nacional para a Proteção dos Seres Humanos em Pesquisa Biomédica e Comportamental) (PESSINI, 1996, p.51).

A sociedade de risco e do conhecimento apesar de dissolver o tradicionalismo concebendo um universo desconhecido, fluido, ambivalente e ameaçador - proporcionou a cura de diversas patologias, e ainda, franqueou a vida extensa, bem como a satisfação de desejos antes considerados etéreos. Este caminhar evolutivo passou a ser delimitado pelas balizas da bioética - ciência que se colocou a serviço de todos -, fundada na primazia pela vida, conforme os ditames da Declaração Universal sobre a Utilização do Progresso Científico e Tecnológico no Interesse da Paz e em Benefício da Humanidade, feita pela ONU em 10 de novembro de 1975, delineados no art. $6^{\circ}$ :

\footnotetext{
"Todos os Estados adotarão medidas tendentes a estender a todos os estratos da população os benefícios da ciência e da tecnologia e a protegê-los, tanto nos aspectos sociais, quanto materiais, das possíveis consequências negativas do uso indevido do progresso científico e tecnológico ou do grupo, em particular relativamente ao respeito à vida privada e à proteção da pessoa humana e de sua integridade física e intelectual".
}

Diante desses registros, compreende-se que a ética científica sobre a vida humana ganhou novo contorno, não ficando restrita ao momento do nascimento e da morte, mas merecendo cuidados quanto à fertilização in vitro, antecipação e retardamento do óbito, mudança de sexo, legalização do aborto, experiências com células-tronco, esterilização, além dos tratamentos com drogas estimulantes e antidepressivas. Nessa perspectiva, a Bioética assumiu enorme relevância na órbita jurídica já que passou a definir os vetores para consolidação dos direitos fundamentais. 


\section{PRINCÍPIO DA PRECAUÇÃO NA PESQUISA CLÍNICA E EXPERIMENTAÇÃO COM SERES HUMANOS}

A modernização dos métodos e técnicas aplicados no campo das ciências médicas e biológicas exigiu o emprego do "homem" como objeto de análise, sujeitando-o a postura de submissão para viabilizar resultados mais aproximados das expectativas reais. Por conseguinte, as pessoas expostas à pesquisa clínica e experimentação se viam diante de riscos e incertezas decorrentes de práticas abusivas. Portanto, os princípios da beneficência e da não maleficência foram estabelecidos como norma de conduta para demarcar os limites da bioética. Nessa perspectiva, Viera e Hossne (1997, p. 8) afirmam que o progresso do conhecimento resulta em benefícios aos futuros pacientes. Contudo, o indivíduo submetido à experiência fica cercado de vulnerabilidades diante dos danos potenciais e concretos que podem ocasionar perdas significativas, havendo, portanto, a necessidade de quantificar e qualificar a justificativa dos prejuízos frente às possibilidades de proveito.

Visando intensificar os esforços para mitigação das perplexidades e das lesões à dignidade humana, em prol do bem comum, é de grande valia a integrar o princípio da precaução como ao conjunto de vetores dirigido à pesquisa e experimentação com seres humanos.

Face aos aspectos da sociedade de risco, à corrida pela conquista do mercado farmacêutico e à ética na pós-modernidade tornou-se imperioso precisar os níveis de aceitabilidade, concernentes às experimentações com seres humanos, a fim de assegurar a prevalência do consenso e da autonomia do paciente (DOUGLAS, 1996, p. 38). Isto é, a latência do comportamento invasivo decorrente da curiosidade científica motivou a intensificação da salvaguarda do consentimento informado e da precaução quanto às metodologias utilizadas na busca pela cura, tal como no tratamento de doentes e averiguação de efeitos colaterais de determinadas substâncias (ZUBEN, 2007, p. 13).

Paradoxalmente, verificou-se que a introdução de barreiras à pesquisa também seria um fator de risco, uma vez que a imposição de limites imponderáveis poderia se converter em ameaça à ordem constitucional alusivo ao dever estatal quanto à permissão e fomento da análise científica voltada para o combate de enfermidades. Com isso, cientistas, técnicos, profissionais da saúde, legisladores e potenciais interessados assumiram a responsabilidade de efetivar equilíbrio entre a prospecção de resultados, interesse social e dignidade humana, tentando conciliarem as múltiplas facetas do Estado democrático de Direito. 
A fim de harmonizar essas fronteiras em favor da ascensão da vida, a Comissão Americana para Proteção dos Participantes Humanos em Pesquisa Biomédica introduziu no âmbito da bioética o princípio da justiça que fixou os delineamentos para justa distribuição dos malefícios derivados das experimentações, na medida em que o recrutamento dos participantes não mais se restringiria a grupos específicos de pessoas, tais como prisioneiros e asilados (GRECO, 2013, p. 23-24). Dessa forma, foi dado maior suporte moral, ético e jurídico à dignidade humana, com intuito de evitar arbitrariedades e atitudes reprováveis, reiteradas durante o nazismo, e, que ainda hoje, fogem do controle dos órgãos reguladores.

Em complementação aos fundamentos da bioética, é aduzida a magnitude da prudência, diante da relevância cognitiva na órbita do Direito Ambiental e da responsabilidade civil, visto que a cega confiabilidade é capaz atrair contingências e incertezas . Nessa acepção, o risco potencial passa a ser alvo da repulsa do legislador, tal como da sociedade, com esteio no princípio da precaução (TRONCOSO, 2010, p. 206-207). Em outras palavras, o estudo da probabilidade assume importante papel, pois diante da constatação de efeitos perniciosos no emprego de determinados métodos, alusivos ao alcance de terapias, remédios para cura de doenças e aquisição de novos conhecimentos ou validação de uma hipótese.

Não é demais frisar que as diretrizes normativas cunhadas na precaução foram incumbidas de conformar metodologia, técnica e utilidade, seguindo os parâmetros do Código de Nuremberg 1946-1947 que consagra o consentimento esclarecido - regra da deontologia Declarações da AMM (Associação Médica Mundial) e proclama os princípios da cientificidade (a responsabilidade pela condução da experimentação deve ser atribuída a um especialista qualificado), da beneficência, já mencionado anteriormente, e da reversibilidade para evitar danos (a experiência não deve ser ensaiada quando houver, a priori, uma razão de se crer que provocará a morte ou a invalidez do sujeito).

O cientista não pode ser tomado pelo fascínio, encantamento ou sedução, porquanto, em consequência de prováveis danos, invalidez e até mesmo morte estará impedido de dar seguimento à sondagem. Sua persistência poderá acarretar ônus incalculáveis ao indivíduo, adstrito à análise, e, dependendo da proporção, repercutir sobre a humanidade. À vista disso, em 1964 durante a XVIII Assembleia Geral da Associação Médica Mundial, realizada em Helsinque foi difundida a Declaração de Helsinque, reeditada com acréscimos por ocasião da Assembleia de Tóquio em 1975, ficando regimentada a "missão do médico", sob a obrigatoriedade de "velar pela saúde do homem" (ZUBEN, 2007, p. 17). Assim, a prévia avaliação comparativa, em torno dos riscos e benefícios à saúde, não só do sujeito da 
experimentação, mas também da coletividade, ficou consignada como pressuposto das experiências com seres humanos.

Nessa acepção, a Associação Médica Mundial (AMM), reunida para a Assembleia geral de Lisboa, em 1981, aprovou a Declaração sobre os Direitos dos doentes. O documento expressou o abandono do "medicocentrismo" paternalista que caracterizava a deontologia tradicional, além de fixar o direito do enfermo de escolher livremente um médico livre; o direito de recusar um tratamento; o direito a confidencialidade; o direito de morrer na dignidade e de receber ou recusar um auxílio espiritual, moral ou religioso.

Em 1987, em Madri, a AMM editou diversas normativas denominadas "Resoluções de Madri”, que reuniram temas atinentes à fecundação in vitro e transferência de embriões, transplante de órgãos humanos; eutanásia, orientação genética e as manipulações genéticas.

Outros diplomas, também fundados no princípio da precaução, foram promulgados por intermédio da AMM, tais como: Declaração de Helsinque-Edimburgo (2000); Declaração Universal sobre o Genoma Humano e os Direitos do Homem da Comissão Internacional de bioética (UNESCO, 1997) e a Convenção sobre os Direitos do homem e a Biomedicina (Conselho da Europa, 1997).

Diante de todo conglomerado de preceitos e princípios assentados na prudência estaria justificada qualquer providência antecipatória manejada pela bioética e pelos operadores do Direito, com propósito de guarnecer o interesse público e a dignidade humana das gerações presente e futuras. Vale salientar que tais intervenções se afastaram do campo da discricionariedade para se aproximar da determinação vinculada.

Em síntese, mesmo na presença de incompletudes informacionais, o princípio da precaução justificaria a execução de medidas prévias alusivas às prováveis ameaças ao bem comum. Significa dizer que o governo estaria autorizado a embargar qualquer prática que demonstrasse risco ao bem-estar coletivo e individual, dentro de uma realidade abstrata (KOURILSKY; VINEY, 1999, p. 11-12).

O princípio da precaução teve origem na década de 70 quando foram proclamadas no Direito alemão, regras para o enfrentamento dos riscos relacionados à degrandação da natureza para suprir as angústias que surgira em decorrência das novas tecnologias da época. Cabe ressaltar que o intuito não era entravar a vigorosa prática comercial das indústrias em crescimento, mas reprimir as ameaças intangíveis (TRONCOSO, 2010, p. 207).

A ascensão do discernimento sobre os impactos ambientais que poderiam ser experimentados nos próximos anos motivara a implantação de uma política de contenção 
antecedente. Sua maior ênfase foi percebida na Conferência Internacional sobre a Proteção do Mar do Norte, em 1987, onde se pretendia estabelecer mecanismos de controle sobre o uso de substâncias perigosas (SUNSTEIN, 2003, p. 1012).

A cautela foi incorporada à legalidade, permitindo às autoridades públicas questionarem a ciência inovadora, as técnicas avançadas e as modernas engenhosidades. O intervencionismo ganhara maior robustez, com intuito de refrear os riscos e ordenar procedimentos para evitação de agravamentos à sociedade (TRONCOSO, 2010, p. 208).

A precaução passou a ser um dever de agir da Administração, bem como dos operadores da medicina (clínica e experimental) e demais ciências biológicas, objetivando a repreensão de expedientes supostamente malignos. Em contrapartida, a exacerbação de medidas precaucionais reverte-se em efeito paralisante a ponto de inviabilizar o progresso científico, social e econômico. Portanto, a conciliação entre os objetivos da experimentação com seres humanos requer uma análise ancorada no princípio da proporcionalidade, com o propósito de coordenar o juízo de valor para atingir melhores escolhas (GUASTINI, 1999, p. 149-150).

Por tudo isso, Hammerschimidt (2002, p. 109) sustenta que a postura precavida se concentra em atitudes adequadas, necessárias e proporcionais ante ao risco presumido de infortúnios que possam recair sobre os direitos fundamentais. A cerca dessa orientação, médicos, biólogos, pesquisadores e demais interessados nos resultados extraídos das experimentações com seres humanos não podem negligenciar qualquer contingência que supere o estado natural das coisas, sob pena de responsabilização pela inobservância do dever de cuidado.

A tensão entre autonomia privada, dignidade humana, progresso científico, interesse econômico, recursos médicos para tratamento clínico da saúde e equilíbrio do meio ambiente ordena um enfrentamento sob a lógica da ponderação, prestigiando sempre decisões capazes de harmonizar, o máximo possível, as variáveis conflitantes (ALVARES, 2013, p. 43).

\section{CONCLUSÃO}

Convém estar consciente de que possivelmente está-se assistindo neste século que recém inicia a um período histórico de caráter eminentemente transitório. Isto é, uma etapa de mudanças em relação à forma de como encarar e explicar a realidade. É possível também que 
se esteja contribuindo para fixar as bases para um novo paradigma de futuro. E que, ao mesmo tempo, essa tensão que é vivida e sofrida pelo ser humano, o faz romper e afastar-se do tempo antecedente, dos modelos ainda vigentes, mas precedentes, para que se oriente numa direção cujo fim ainda lhe é desconhecida de todo.

É certo que o progresso científico promoveu aumento da expectativa de vida das pessoas, além de ter proporcionado maior comodidade, otimização do tempo e minimização das distâncias. Ademais, viabilizou a descoberta da cura para diversas doenças, bem como elevou os graus de eficiência e eficácia no tratamento de pacientes acamados.

Nem tudo saiu conforme planejado, pois a discricionariedade técnica foi manejada com certa exacerbação no decorrer da evolução das pesquisas, razão pela qual a bioética passou a servir de fundamento para os métodos e práticas utilizados por profissionais da saúde, biólogos, cientistas, farmacêuticos dentre outros envolvidos na manipulação de material genético e experimentações com seres humanos. Nessa perspectiva, a AMM (Associação Médica Mundial) elaborou um conjunto de normativas, com intuito de conter abusos das ciências biológicas e definir os graus de aceitabilidade quanto às ameaças incidentes sobre os indivíduos.

Levando em consideração a insuficiência da legalidade estrita e a pouca expressividade dos vetores da bioética em torno da mitigação dos prejuízos ao interesse público e à dignidade humana, ficou constada a magnitude do princípio da precaução como paradigma para administração responsável da vida humana, animal e ambiental, uma vez que sua essência se demonstrara consubstanciada na harmonia da dignidade, do progresso científico e da salvaguarda dos direitos fundamentais das futuras gerações.

Assim, a partir de agora já é possível entrever que, por exemplo, as possibilidades da informática e da biotecnologia são tão impressionantes que o futuro se configura como um oceano imenso, de contornos e limites imprecisos, salpicado de incertezas, possibilidades, riscos e ao mesmo tempo de excitantes expectativas.

Importante destacar que a tensão entre os anseios da comunidade universal deve ser resolvida com amparo na ponderação, sob os prismas da proporcionalidade e da razoabilidade, já que o excesso de precaução tem por inconveniente o efeito paralisante do desenvolvimento.

Não é demais lembrar que a condição humana é, em si, incompatível com a certeza e a segurança absoluta. Daí a importância do aporte bioético para promover e propiciar um uso responsável da aplicação do conhecimento. Isso requer um manejo adequado das práticas invasivas, tendo em consideração o princípio da beneficência e o consentimento esclarecido. A natureza demonstrou que não existem pessoas inferiores em relação outras, mas a história 
apontou que os poderes econômicos subjugaram a vida das camadas mais estratificadas. A minorias foram objeto da busca pela descoberta de super-humanos e hoje as relações de consumo avançam sobre o ecossistema, causando inconvenientes à sociedade contemporânea, além de colocar sob ameaça os direitos fundamentais das gerações futuras.

Ninguém pode ser rebaixado ao status de coisa já que o ordenamento jurídico impõe deveres de proteção e promoção ao mínimo existencial, sendo vedado o retrocesso nos moldes do Estado patrimonialista. $\mathrm{O}$ açoite, a tortura e o genocídio foram práticas reconhecidas como repugnantes e, portanto, rechaçada pelo Estado democrático de direito, não restando espaço para reeditá-las de modo velado.

A redefinição das regras de precaução e prevenção, tal como as normas punitivas não âmbito da bioética devem ser elevadas à níveis de maior rigidez, reclamando também o aparelhamento dos órgãos de fiscalização para viabilizar o controle efetivo, eficiente e eficaz das pesquisas e manipulações, com propósito de conter os excessos exercidos pela ciência.

\section{REFERÊNCIAS BIBLIOGRÁFICAS}

ANDERSON, Perry. As origens da pós-modernidade. Trad. Marcus Penchel. Rio de Janeiro: Jorge Zahar, 1999.

ALVARES, Mariell Antonini Dias. Princípio da Precaução como instrumento adequado para resolução dos problemas ambientais de segunda geração. Revista de Direito Ambiental, ano 18, vol. 71, jul/set, 2013, p. 35-52.

BAUMAN, Zygmunt. Modernidade e ambivalência. Tradução de Marcus Penchel. Rio de Janeiro: Jorge Zahar Ed., 1999. Título original: Modernity and ambivalence.

O Mal Estar da Pós-Modernidade. Tradução Mauro Gama, Claudia Martinelli Gama: revisão técnica: Luís Carlos Fridman. Rio de Janeiro: Jorge Zahar Ed., 1998.

BECK, Ulrich. Sociedade de Risco: rumo a uma outra modernidade. Tradução de Sebastião Nascimento. São Paulo: Editora 34, 2010.

BELlATO, Roseney; CARVALHO, Emília Campos de. O Jogo Existencial e a Ritualização da Morte. Revista Latino-americana de Enfermagem. Vol.13-1, janeiro-fevereiro, 2005, p. 99104. Disponível em:<www.eerp.usp.br/rlae> Acesso 04 abr. 2015.

BRÜSEKE, Franz Josef. A Modernidade Técnica. Revista Brasileira de Ciências Sociais - vol. 17, nº 49, junho, 2002, pp. 135-173. 
DE GIORGI, Raffaele. O Risco na Sociedade Contemporânea. Revista de Direito Sanitário, São Paulo, v. 9, nº 1, mar/jun., 2008, p. 37-49.

DOUGLAS, M. La aceptabilidad del riesgo según las ciencias sociales. Barcelona: Paidós Studio, 1996.

ENGELHARDT Jr. The foundations of Christian bioethics. Lisse, Netherlands: Swets \& Zeitlinger, 2000.

GRECO, Dirceu B. Emancipação na luta pela equidade em pesquisas com seres humanos. Revista Bioética, vol. 21, no 1, 2013, p. 20-31.

GUASTINI, Riccardo. Distinguiendo: estúdios de teoria y metateoría del derecho. Barcelona: Gedisa, 1999.

GUERRA, Sérgio. Transformações do Direito Administrativo e a (In) Segurança Jurídica. Revista Eletrônica sobre a Reforma do Estado (RERE). Salvador, Instituto Brasileiro de Direito Público, $\mathrm{n}^{\circ}$ 17, 2009. Disponível em: <http://www.direitodoestado.com.br/rere.asp>. Acesso em: 04 abr. 2015.

HAMMERSCHMIDT, Denise. O Risco na Sociedade Contemporânea e o Princípio da Precaução no Direito Ambiental. Revista Seqüência. Universidade Federal do Paraná. Estudos Jurídicos e Políticos, n. ${ }^{\circ}$ 45, 2002, p. 97-122. Disponível em: <www.periodicos.ufsc.br/index.php/sequencia/article/view/15317/13912>. Acesso em: 04 abr. 2015 .

HECK, J. N. Bioética: Contexto Histórico, Desafios e Responsabilidade. Revista ethic@, Florianópolis, v.4, n.2, Dez./2005, p.123-139.

INTERNATIONAL CONFERENCE ON THE PROTECTION OF THE NORTH SEA, 1987 London. Ministereal Declaration. Stockolm: Government Offices of Sweden, 2008.

JONAS, Hans. El principio de reponsabilidad. Ensayo de una ética para la civilización tecnológica. Barcelona: Herder, 1995.

KANE, John; PATAPAN, Haig. In Seach of Prudence: The Hidden Problem of Managerial Reform. Public Administration Review, v. 66, Issue 5, sep./oct., 2006, p. 711-724.

KOURILSKY, Philippe; VINEY, Geneviève. Le principe de précaution: rapport au Premier Ministre. Disponível em: <http://www.ladocumentationfrancaise.fr/var/storage/rapportspublics/004000402/0000.pdf > Acesso em: 04 abr 2015.

MARTINÉZ, Á. García de Jalón (et. al.). Transplante Renal. técnica y complicaciones. Actas Urológicas Españolas; Elsevier, volume 27, issue 9, 2003, p. 662-677.

MOREIRA NETO, Diogo de Figueiredo. Quatro paradigmas do direito administrativo pósmoderno: legitimidade; finalidade; eficiência; resultado. Belo Horizonte: Fórum, 2008. 
MORI, Maurizio. A Bioética: sua natureza e história. In:BRASIL. Ministério da Saúde. Secretaria de Ciência, Tecnologia e Insumos Estratégicos. Departamento de Ciência e Tecnologia. Capacitação para Comitês de Ética em Pesquisa - CEPs/Ministério da Saúde/Ministério da Saúde, Secretaria de Ciência, Tecnologia e Insumos Estratégicos, Departamento de Ciência e Tecnologia. - Brasília : Ministério da Saúde, 2006.

PESSINI, L. O desenvolvimento da Bioética na América Latina. Algumas Considerações. In: PESSINI, L.; BARCHIFONTAINE, C. de P. (orgs.). Fundamentos da Bioética. $1^{\text {a }}$ ed., Cap. 1. São Paulo: Paulus, 1996.

RANDALL JR. The making of modern mind. New York: Columbia University Press, 1976.

ROTANIA, Alejandra Ana. A Celebração do Temor: Biotecnologias, Reprodução, Ética e Feminismo. Rio de Janeiro: E-Papers, 2001.

SECRETARÍA DEL TRATADO ANTÁRTICO. Protocolo al Tratado Antártico sobre Protección del Meio Ambiente. Disponível em: <http://www.ats.aq/documents/recatt/Att006_s.pdf>. Acesso em: 04 abr 2015.

SILVEIRA, Fernando Lang. A Premissa Metafísica da Revolução Copernicana. Caderno Brasileiro de Ensino de Física - UFSC, v. 19, n. 1, abr., 2002, p. 29-52.

SUNSTEIN, Cass R. Beyond the Precautionary Principle. University of Pennsylvania Law Review, vol.151, no. 3, 2003, p. 1003-1058.

TESSER, C. D. Medicalização social (I): o excessivo sucesso do epistemicídio moderno na saúde. Interface - Comunic., Saúde, Educ., v.10, n.19, jan/jun 2006, p.61-76.

TRONCOSO, María Isabel. El principio de precaución y la responsabilidade civil. Revista de Derecho Privado, Bogotá: Univerisidad Externado de Colombia, vol. 18, 2010, p. 205-220.

VIEIRA, Sonia; HOSSNE, William Saad. Experimentação com Seres Humanos. Ciência \& Ensino - UNICAMP, vol. 2, jul. 1997, p. 7-9. Disponível em: $<$ http://prc.ifsp.edu.br/ojs/index.php/cienciaeensino/article/viewFile/11/17>. Acesso em $04 \mathrm{abr}$ 2015.

ZUBEN, Newton Aquiles von. As investigações científicas e a experimentação humana: aspectos bioéticos. Revista Bioethikos - Centro Universitário São Camilo -; vol 1, nº 1, jan./jun., 2007, p. 12-23. 